\title{
Optimization of concrete I-beams using a new hybrid glowworm swarm algorithm
}

\section{Abstract}

In this paper a new hybrid glowworm swarm algorithm (SAGSO) for solving structural optimization problems is presented. The structure proposed to be optimized here is a simply-supported concrete I-beam defined by 20 variables. Eight different concrete mixtures are studied, varying the compressive strength grade and compacting system. The solutions are evaluated following the Spanish Code for structural concrete. The algorithm is applied to two objective functions, namely the embedded $\mathrm{CO}_{2}$ emissions and the economic cost of the structure. The ability of glowworm swarm optimization (GSO) to search in the entire solution space is combined with the local search by Simulated Annealing (SA) to obtain better results than using the GSO and SA independently. Finally, the hybrid algorithm can solve structural optimization problems applied to discrete variables. The study showed that large sections with a highly exposed surface area and the use of conventional vibrated concrete $(\mathrm{CVC})$ with the lower strength grade minimize the $\mathrm{CO}_{2}$ emissions.

\section{Keywords}

Hybrid glowworm swarm algorithm, discrete variables, concrete Ibeam, $\mathrm{CO}_{2}$ emissions, self-compacting concrete.

\author{
Tatiana García-Segura ${ }^{\text {a }}$ \\ Víctor Yepes ${ }^{b}, *$ \\ José V. Martí c \\ Julián Alcalá d \\ ${ }^{a}$ Graduate Research Assistant, ICITECH, \\ Dept. of Construction Engineering, Universi- \\ tat Politècnica de València, 46022 Valencia, \\ Spain. \\ ${ }^{\mathrm{b}}$ Associate Professor, ICITECH, Dept. of \\ Construction Engineering Universitat Politèc- \\ nica de València, 46022 Valencia, Spain. \\ Corresponding author. Phone +34963879563 ; \\ Fax +34963877569 .

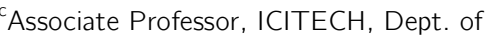 \\ Construction Engineering Universitat Politèc- \\ nica de València, 46022 Valencia, Spain. \\ ${ }^{d}$ Assistant Professor, ICITECH, Dept. of \\ Construction Engineering Universitat Politèc- \\ nica de València, 46022 Valencia, Spain. \\ Author e-mail: vyepesp@cst.upv.es
}

\section{INTRODUCTION}

The traditional goals of engineers are the design of safe and economic structures. However, there is a growing concern for sustainability about the need to protect the environment. Now, more than ever, engineers should choose environmentally-friendly materials and cross-section dimension to minimize the impact of their projects as well as the consumption of natural resources. In this context, the so-called metaheuristics methods have shown to be highly suited to design structures (Hare et al., 2013). While the design of economic structures has always been conditioned by the 
experience of structural engineers, metaheuristic methods have recently provided efficient structures with a reasonable computing time.

Optimization of reinforced concrete (RC) structures has been investigated by many researchers in the past. A thorough review of nonheuristic structural concrete optimization studies can be found in Sarma and Adeli (1998). Many later studies have been undertaken to implement evolutionary algorithms to solve structural concrete optimization problems (Kicinger et al., 2005), while the present authors' research group reported on non-evolutionary algorithms to optimize real-life RC structures (Payá-Zaforteza et al., 2010; Yepes et al., 2012; Carbonell et al., 2012; Martí et al., 2013; Martínez-Martín et al., 2013; Torres-Machí et al., 2013).

Swarm intelligence is a type of biologically-artificial intelligence based on neighbour interactions. It imitates the collective behaviour of some agents which follow a global pattern. They interact with one another and learn from it. In fact, these algorithms differ in philosophy from genetic algorithms because they use cooperation rather than competition (Dutta et al., 2011). Particle swarm optimization (PSO) simulates a simplified social system (Kennedy and Eberhart, 1995). Ant colony optimization (ACO) was proposed by Colorni et al. (1991) simulating the behaviour of ants leaving pheromone to guide others. Artificial bee colony (Basturk and Karaboga, 2006; Karaboga and Basturk, 2008) mimics the food forage behaviour of honeybees. The glowworm swarm optimization (GSO) algorithm was proposed by Krishnanand and Ghose (2009) to obtain multiple optima of multimodal functions. This algorithm imitates a glowworm carrying luciferin and moving towards a mate whose luciferin level is higher than its own (Liao et al., 2011; Gong et al., 2011; Luo and Zhang, 2011; Khan and Sahai, 2012). However, Qu et al. (2011) pointed out its low convergence rate; what is more, this algorithm can be effective for searching a local optimum, but some shortcomings exist for searching the global optimum solution (Zhang et al., 2010).

The main purpose of this paper is to demonstrate how the standard GSO can be improved by incorporating a hybridization strategy. A hybrid GSO algorithm (SAGSO) is proposed, combining the broad search ability of GSO and SA effectiveness to find a global optimum to speed up the local search. Hybrid GSO has already been proposed combining a simplex search method (Qu et al., 2011), chaos optimization mechanism (Zhang et al., 2010), Hooke-Jeeves pattern search (Yang et al., 2010) and differential evolution (Luo and Zhang, 2011). In fact, the results showed that the hybrid algorithm had faster convergence, higher accuracy and was more effective for solving constrained engineering optimization problems (Luo and Zhang, 2011). Hybrid PSO optimization has also been widely applied (Shieh et al., 2011; Valdez et al., 2011; Fan and Zahara, 2007; Ahandania et al., 2012; Li et al., 2009; Wang et al., 2013) demonstrating faster convergence rates. Likewise, ACO was improved by incorporating a hybridization strategy (Chen et al., 2012; Koide et al., 2013).

This paper describes a new hybrid algorithm applied to two objective functions, namely the embedded $\mathrm{CO}_{2}$ emissions and the economic cost. For the design of a simply supported concrete IBeam, 20 discrete variables were used. The optimization compares self-compacting concrete (SCC) with conventional vibrated concrete (CVC), as well as four different compressive strength classes. 


\section{THE OPTIMUM DESIGN PROBLEM}

The structural design problem established for this study aims to minimize the objective function $F$ of equation (1), subject to the constraints represented by equation (2).

$$
\begin{gathered}
F\left(x_{1}, x_{2}, \ldots, x_{n}\right) \\
g_{j}\left(x_{1}, x_{2}, \ldots . x_{n}\right) \leq 0 \\
x_{i} \in\left(d_{i 1}, d_{i 2}, \ldots, d_{i q_{i}}\right)
\end{gathered}
$$

Note that $x_{1}, x_{2}, \ldots, x_{\mathrm{n}}$ are the variables to be optimized (design variables). Each design variable may assume the discrete values listed in equation (3). The objective function $F$ defined in equation (1) is either the cost or the $\mathrm{CO}_{2}$ emission. The constraints $g_{j}$ in equation (2) are all the service limit states (SLSs) and ultimate limit states (ULSs) with which the structure must comply, as well as the geometrical and constructability constraints of the problem. The following sections describe the problem in detail.

\subsection{Design variables and parameters}

The case considered here is a simply supported concrete I-beam (see Figure 1). The problem is formulated with 20 variables. Seven variables define the geometry: the depth $(h)$, the width of superior flange $\left(b_{f_{s}}\right)$, the width of inferior flange $\left(b_{f i}\right)$, the thickness of the superior flange $\left(t_{f_{s}}\right)$, the thickness of the inferior flange $\left(t_{f i}\right)$, the web thickness $\left(t_{w}\right)$ and the concrete cover $(r)$. Another variable establishes the concrete mix: four mixes of SCC and four mixes of CVC represent four strength classes. The mixtures are described by Sideris and Anagnostopoulos (2013). All mixtures use crushed limestone.

Finally, passive reinforcement is defined by the number and diameter of the bars. The longitudinal reinforcement is arranged in longitudinal upper reinforcement $\left(n_{1}, \varnothing_{1}\right)$, covering the whole beam length. Lower reinforcement is divided in two systems, one covering the whole beam length $\left(n_{2}, \varnothing_{2}\right)$ and another covering the central part of the beam $\left(n_{3}, \varnothing_{3}\right)$. Transversal and longitudinal shear reinforcement changes between two zones, support zone as length of $L / 5$ near the supports and central zone. Shear reinforcement is defined by the number of bars per meter and their diameter in the support zone $\left(n_{4}, \varnothing_{4}\right)$ and in the central zone $\left(n_{5}, \varnothing_{5}\right)$. The number of bars per meter of transversal and longitudinal shear reinforcement is equal, while the diameter can change. Therefore, four variables define the longitudinal shear reinforcement: the support zone $\left(n_{4}, \varnothing_{6}\right)$ and the central zone $\left(n_{5}\right.$, $\left.\emptyset_{7}\right)$. 

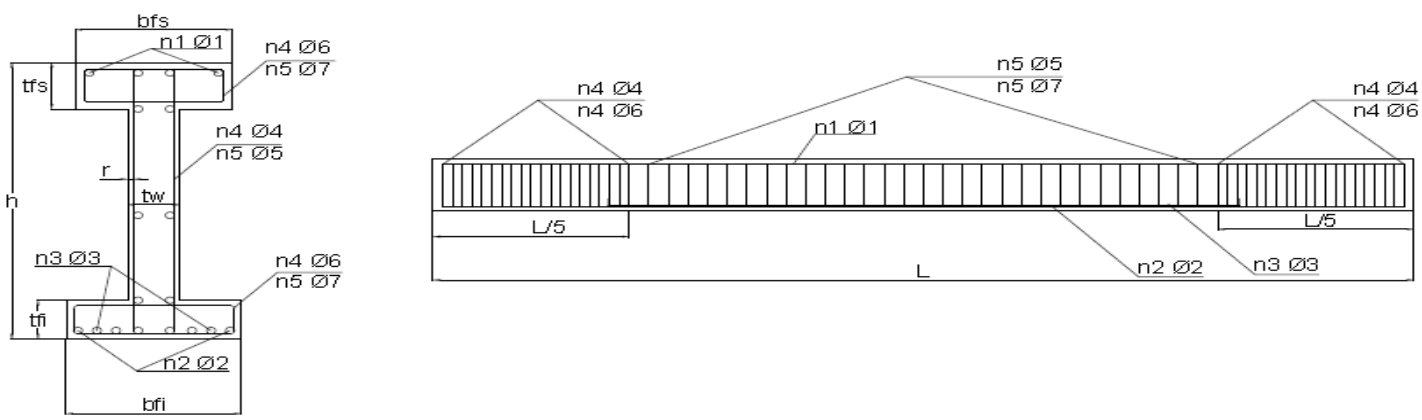

Figure 1 Design variables of the simply supported concrete I-beam.

The parameters of the I-beam are all fixed quantities that do not change during the optimization, including the beam span $(15 \mathrm{~m})$, the permanent distributed load $(20 \mathrm{kN} / \mathrm{m})$, and the variable distributed load $(10 \mathrm{kN} / \mathrm{m})$.

\subsection{Structural constraints}

Considering all the data necessary to define a given structure, the structural evaluation module calculates the stress envelopes and checks all the limit states and the geometric constraints represented by equation (2). Serviceability and ultimate limit states (SLS and ULS) must be guaranteed following the Spanish Standard EHE-08 (Fomento, 2008). As for the instantaneous and timedependent deflection of the central section, a limitation of $1 / 250$ of the beam span for quasipermanent loading conditions is imposed. Besides, if the section does not comply with the geometrical and constructability constraints, it is rejected.

One hundred years are required for the service life. The study was developed by evaluating durability according to the EHE code (Fomento, 2008). The code presents durability of a concrete structure as its capacity to withstand, for the duration of its designed service life, the physical and chemical conditions to which it is exposed. Carbonation is the main factor leading to RC decay. Service life of RC structures is assessed as the sum of two phases, according to equation (4). This mode is based on the Tuutti (1982) model. The first phase is initiation of corrosion, in which carbonation penetration in the concrete cover means the loss of reinforcement passivity. The second phase involves the propagation of corrosion that begins when the steel is depassivated and ends when a limiting state is reached beyond which the consequences of corrosion can no longer be tolerated.

$$
t=\left(\frac{d}{k}\right)^{2}+\frac{80 \cdot d}{\varphi \cdot v_{c}}
$$

where, $t$ are the years of service life; $d$ is concrete cover $(\mathrm{mm}) ; k$ is the carbonation rate coefficient; $\varphi$ is the bar diameter $(\mathrm{mm})$, and $v_{c}$ is the corrosion rate $(\mu \mathrm{m} /$ year). The carbonation rate coefficient of all SCC and CVC mixtures was evaluated by Sideris and Anagnostopoulos (2013). The 
values of the compressive strength and carbonation rate coefficient are presented in Table 1 . In a general exposure, like IIb, the corrosion rate is about $2 \mu \mathrm{m} /$ year (Fomento, 2008).

Table 1 Mix design properties and cement content.

\begin{tabular}{cccc}
\hline \hline Description & Compressive strength $(\mathrm{MPa})$ & $k\left(\mathrm{~mm} /\right.$ year $\left.^{0.5}\right)$ & Cement $\left(\mathrm{kg} / \mathrm{m}^{3}\right)$ \\
\hline Concrete SCC1 & 35.80 & 7.42 & 302 \\
Concrete SCC2 & 45.30 & 5.14 & 336 \\
Concrete SCC3 & 54.20 & 3.40 & 374 \\
Concrete SCC4 & 57.10 & 1.45 & 436 \\
Concrete CVC1 & 31.10 & 9.99 & 300 \\
Concrete CVC2 & 41.00 & 6.23 & 330 \\
Concrete CVC3 & 52.70 & 3.65 & 370 \\
Concrete CVC4 & 56.70 & 1.49 & 450 \\
\hline
\end{tabular}

\subsection{Objective functions}

The economic cost and the embedded $\mathrm{CO}_{2}$ emissions are the objective functions to be minimized. The objective functions measure the cost and the $\mathrm{CO}_{2}$ emissions of the RC production and placement. The basic prices and emissions considered, given in Table 2, were obtained from the 2013 BEDEC ITEC database of the Institute of Construction Technology of Catalonia (BEDEC, 2013). Concrete unit price and $\mathrm{CO}_{2}$ emissions were determined from each mix design, including transport and placing (García-Segura et al., 2014). Concerning the plasticizer used, $\mathrm{CO}_{2}$ emissions were those given by the European Federation of Concrete Admixtures Associations, since it distinguishes between plasticizer (EFCA, 2006a) and superplasticizer (EFCA, 2006b). It is considered that the silica fume does not produce emissions, since it is a waste product (García-Segura et al., 2014). Finally, the cost of $\mathrm{CO}_{2}$ emissions was that given in $\mathrm{SENDECO}_{2}(2013)$.

Table 2 Unit prices and emissions considered in the RC I-beam.

\begin{tabular}{cccc}
\hline \hline Unit & Description & Cost $(€)$ & $\mathrm{CO}_{2}$ emission $(\mathrm{kg})$ \\
\hline $\mathrm{m}^{3}$ & Concrete SCC1 & 86.01 & 282.46 \\
$\mathrm{~m}^{3}$ & Concrete SCC2 & 93.06 & 312.01 \\
$\mathrm{~m}^{3}$ & Concrete SCC3 & 96.27 & 343.12 \\
$\mathrm{~m}^{3}$ & Concrete SCC4 & 124.33 & 400.10 \\
$\mathrm{~m}^{3}$ & Concrete CVC1 & 99.32 & 278.56 \\
$\mathrm{~m}^{3}$ & Concrete CVC2 & 102.87 & 303.48 \\
$\mathrm{~m}^{3}$ & Concrete CVC3 & 106.52 & 336.10 \\
$\mathrm{~m}^{3}$ & Concrete CVC4 & 113.95 & 401.42 \\
$\mathrm{t}$ & Steel B-500-SD & 1237.59 & 3031.50 \\
$\mathrm{~m}^{2}$ & Formwork in beams & 33.81 & 2.08 \\
$\mathrm{~m}$ & Beam placing & 16.86 & 39.43 \\
$\mathrm{t} \cdot \mathrm{CO}_{2}$ & European CO 2 price & 6.00 & \\
\hline \hline
\end{tabular}

Latin American Journal of Solids and Structures 11 (2014) 1190-1205 
Carbonation captures $\mathrm{CO}_{2}$ and therefore, this capture should be subtracted from the embedded $\mathrm{CO}_{2}$ emissions. This $\mathrm{CO}_{2}$ capture was estimated based on the predictive models of Fick's First Law of Diffusion (Collins, 2010; Lagerblad, 2005). Equation (5) estimates $\mathrm{CO}_{2}$ capture as the product of the carbonation rate coefficient $k$, the structure service life $t$, the quantity of Portland cement per cubic meter of concrete c, the amount of $\mathrm{CaO}$ content in Portland cement (assumed to be 0.65), the proportion of calcium oxide that can be carbonated $r$ (assumed to be 0.75 (Lagerblad, 2005)), the exposed surface area of concrete $A$, and the chemical molar fraction $\mathrm{M}\left(\mathrm{CO}_{2} / \mathrm{CaO}\right.$ is 0.79$)$. The quantity of Portland cement per cubic meter of concrete of every mixture is provided in Table 1.

$$
\mathrm{CO}_{2}=k \cdot \sqrt{t} \cdot c \cdot \mathrm{CaO} \cdot r \cdot A \cdot M
$$

\section{RESULTS}

GSO was originally proposed by Krishnanand and Ghose (2009) to find solutions to the optimization of multiple optima continuous functions. GSO is a swarm intelligence algorithm based on the release of luciferin by glowworms. This luciferin attracts glowworms creating a movement toward another glowworm that is in its neighbourhood and glows brighter. The choice is encoded by a probabilistic function and the neighbourhood by a dynamic radial rate. The luciferin level depends on the fitness of its location, which is evaluated using the objective function.

GSO based algorithms present three main drawbacks: the glowworms may get stuck in local optima, they easily fall into an unfeasible solution and they have slow convergence rate. To overcome these problems, a hybridized method combining simulating annealing and glowworm swarm optimization (SAGSO) algorithms is proposed. Simulated annealing (SA) can escape from the local optima thanks to its probabilistic jumping property. Besides, SA accelerates convergence to the optimum.

Simulated annealing was originally proposed by Kirkpatrick et al. (1983) to design electronic circuits. This algorithm is based on the analogy of crystal formation from masses melted at high temperature and cooled slowly to allow atoms to align themselves reaching a minimum energy state. The probability of accepting new solutions is governed by the expression exp $(-\Delta E / T)$, where $\Delta E$ is the increment in energy of the new configuration and $T$ is the temperature. The initial temperature $T_{0}$ is usually adjusted following methods like that proposed by Medina (2001). The initial temperature is halved when the percentage of acceptances is greater than 40\%, and the initial temperature is doubled if it is less than 20\%. An exponential annealing schedule is adopted using a cooling rate $k$ to control the temperature decrement once a Markov chain $M_{c}$ ends. Hence, the probability of accepting a worse solution drops with each $M_{c}$. The temperature decrement is given by

$$
T_{i+1}=k T_{i}
$$

where $T_{i}$ and $T_{i+1}$ are the system temperatures at $i$ and $i+1$ iteration. The minimum and maximum cooling rate $k$ values used are given in Table 3 .

Latin American Journal of Solids and Structures 11 (2014) 1190-1205 
After a glowworm movement, SA updates the glowworm position with a local search strategy. Figure 2 shows a flowchart of the simulated process. The algorithm ends when the number of iterations $t$ reaches the maximum $t_{\max }$. The SAGSO algorithm is presented below.

1. A swarm of $n$ feasible glowworms is randomly generated within the search space. To each glowworm, several parameters are assigned: initial luciferin value $l_{0}$, initial radial sensor range $r_{s}$, and initial temperature $T_{0}$. After assessing each glowworm objective function, the worst objective value $A$ is chosen.

2. The luciferin value is updated as the sum of the two terms, according to equation (7). The first term simulates the reduction in luciferin level with time, and the second term represents the enhancement of the value of the objective function. As the algorithm must minimize both objective functions, the second term is modified. The difference between the worst objective value $\mathrm{A}$ and the value of the objective function at time $t+1$ is evaluated.

$$
l_{i}(t+1)=(1-\rho) \cdot l_{i}(t)+\gamma\left(A-J\left(x_{i}(t+1)\right)\right)
$$

where: $l_{i}$ is the previous luciferin level; $J\left(x_{i}\right)$ is the objective function; $\varrho$ is the luciferin value decay constant $(0<\varrho<1)$, and $\gamma$ is the luciferin enhancement constant $(0<\gamma<1)$.

3 . The probability of moving toward a neighbour $j$ is given by the equation (8), where $j \in N_{i}(t), N_{i}(t)=\left\{j: d_{i j}<r_{d}^{i}(t) ; l_{i}(t)<l_{j}(t)\right\} . N_{i}(t)$ is the set of neighbours of the glowworm $i$ at the iteration $t$. The neighbours must have higher luciferin value, they must be located within the radial sensor range $r_{d}^{i}(t)$ and they must be feasible solutions. Distance $d_{i j}$ represents the Euclidean distance between glowworms $i$ and $j$.

$$
p_{i j}(t)=\frac{l_{j}(t)-l_{i}(t)}{\sum_{k \in N_{i}(t)} l_{k}(t)-l_{i}(t)}
$$

4. Equation (9) defines the glowworm $i$ movement toward the chosen glowworm $j$. Here, $s(>0)$ is the step size. Although GSO was based on continuous variables, this algorithm adapts the new position to the closest discrete position thanks to the discrete nature of the structural variables. This proposal was already assumed for the PSO algorithm (Parsopoulos and Vrahatis, 2002; He et al., 2004).

$$
x_{i}(t+1)=\operatorname{int}\left[x_{i}(t)+s\left(\frac{x_{j}(t)-x_{i}(t)}{d_{i j}}\right)\right]
$$

5. The radial sensor range is updated (6) according to equation (10), where: $\beta$ is a constant parameter, and $n_{t}$ is a parameter to control the number of neighbours. The new solution is checked and evaluated. Although the new solution is unfeasible, it is accepted. In this case, the objective function is penalized. 


$$
r_{d}^{i}(t+1)=\min \left\{r_{s}, \quad \max \left[r_{d}^{i}(t)+\beta\left(n_{t}-\left|N_{i}(t)\right|\right)\right]\right\}
$$

6. A total $n_{M}$ Markov chains are run. The solution is modified by a small random movement; $n_{v}$ variables are modified by a small random variation higher or lower to the values of these $n_{v}$ variables.

7. The solution is evaluated. Only feasible solutions whose probability is greater than a random number between 0 to 1 are accepted.

$$
\text { random }<e^{\frac{J\left(x_{i}(t)\right)-J\left(x_{i}(t+1)\right)}{T}}
$$

8. When the Markov chain ends, the temperature decreases according to equation (6).

\section{RESULTS USING SAGSO METHOD}

In this section, we examine the results from computational experiments involving SAGSO optimization applied to a simply supported concrete I-Beam with a $15 \mathrm{~m}$ span, considering the parameters defined in section 2.1. The algorithm was coded in Intel@ Visual Fortran Compiler Integration for Microsoft Visual Studio 2010 with a INTEL@ CoreTM i7-3820 CPU processor with 3.6 GHz.

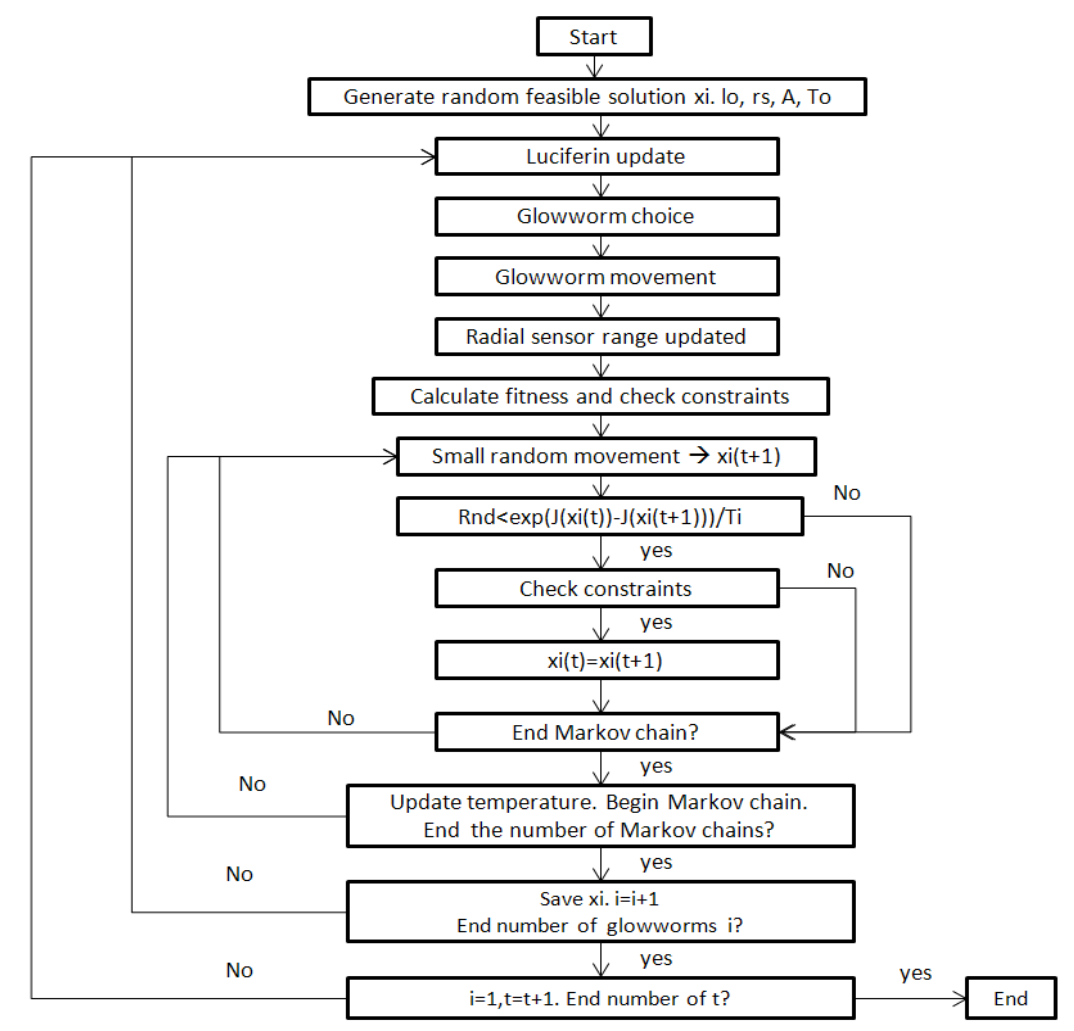

Figure 2 SAGSO flowchart. 
To define the SAGSO parameters $\left(t_{\max }, n, n_{t}, l_{0}, r_{s}, \varrho, \gamma, \beta, s, n_{M}, k, M_{c}, n_{v}\right)$, the algorithm was run 3600 times. Each of the 400 combinations of parameters was performed nine times to obtain statistical data of the results. The parameters were randomly generated between their minimum and maximum values given in Table 3. Figure 3 shows the average cost and the computing time of each run. Tables 4 and 5, respectively, give the statistical results and the parameters of the best values when both cost and computing time are considered.

Table 3 Values of glowworm swarm parameters.

\begin{tabular}{lccc}
\hline \multicolumn{1}{c}{ Parameter } & Minimum & Maximum & Steps \\
\hline Maximum number of iterations $t_{\text {max }}$ & 5 & 15 & 5 \\
Number of glowworms $n$ & 10 & 40 & 10 \\
Number of neighbours $n_{t}$ & 5 & 15 & 5 \\
Initial luceferin value $l_{0}$ & 1000 & 4000 & 1000 \\
Radial sensor range $r_{s}$ & 30 & 70 & 10 \\
Luciferin value decay constant $\varrho$ & 0.30 & 0.70 & 0.20 \\
Luciferin enhancement constant $\gamma$ & 0.30 & 0.70 & 0.20 \\
Constant parameter $\beta$ & 0.05 & 0.08 & \\
Step size $s$ & 10 & 30 & 10 \\
Number of Markov chains $n_{M}$ & 1 & 3 & 1 \\
Coefficient of cooling $k$ & 0.80 & 0.95 & 0.05 \\
Markov chain $M_{c}$ & 500 & 1500 & 500 \\
Modified variables $n_{v}$ & 3 & 4 & \\
\hline \hline
\end{tabular}

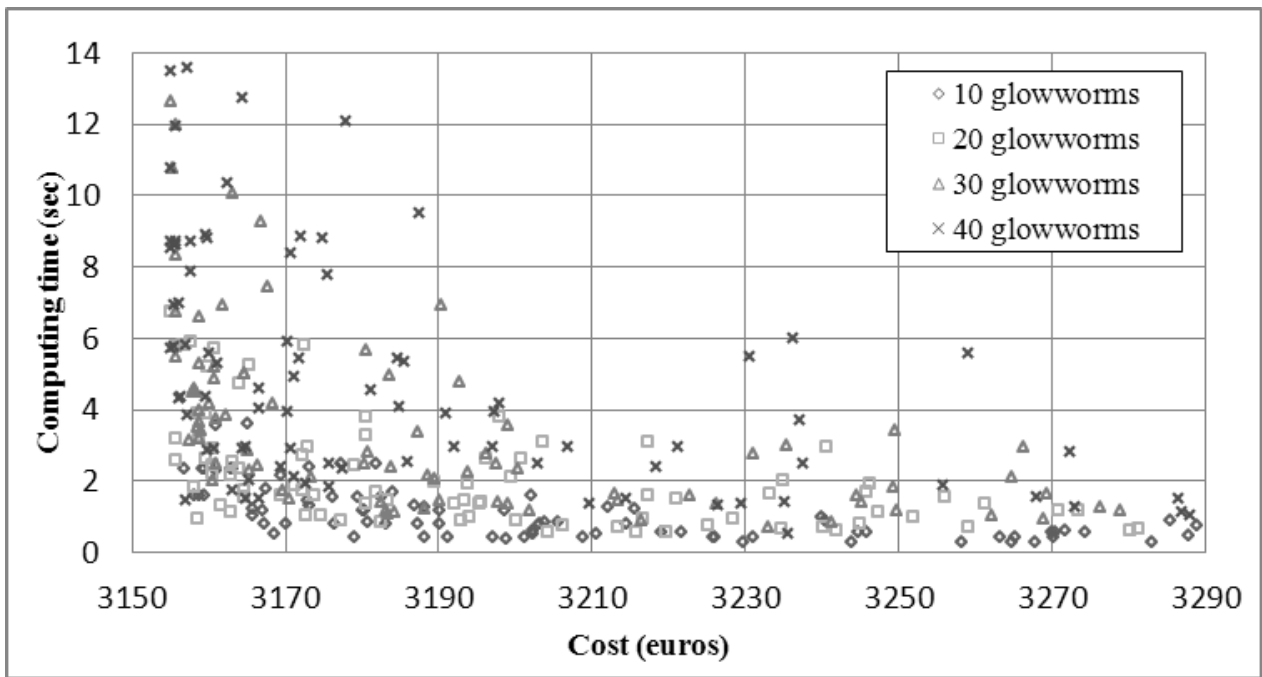

Figure 3 Average cost results of SAGSO. 
Table 4 Statistical results of the best values for the minimum cost of SAGSO.

\begin{tabular}{ccccc}
\hline \hline Solution & Minimum cost $(€)$ & Average cost $(€)$ & Standard deviation $(€)$ & Average time (sec) \\
\hline S1 & 3155.17 & 3155.17 & 0.00 & 10.78 \\
S2 & 3155.17 & 3155.17 & 0.00 & 8.71 \\
S3 & 3155.17 & 3155.17 & 0.00 & 8.53 \\
S4 & 3155.17 & 3155.17 & 0.00 & 6.72 \\
S5 & 3155.17 & 3155.17 & 0.00 & 5.71 \\
S6 & 3155.17 & 3155.70 & 1.19 & 3.20 \\
S7 & 3155.17 & 3155.78 & 0.98 & 2.57 \\
S8 & 3155.17 & 3156.94 & 2.03 & 2.34 \\
S9 & 3155.17 & 3157.02 & 1.77 & 1.47 \\
\hline \hline
\end{tabular}

Table 5 Parameters of the best values for the minimum cost of SAGSO.

\begin{tabular}{cccccccccccccc}
\hline \hline Solution & $n$ & $n_{t}$ & $l_{0}$ & $r_{s}$ & $\varrho$ & $\gamma$ & $\beta$ & $s$ & $n_{v}$ & $M_{c}$ & $k$ & $t_{\max }$ & $n_{M}$ \\
\hline S1 & 40 & 15 & 3000 & 40 & 0.50 & 0.30 & 0.05 & 10 & 3 & 1500 & 0.90 & 15 & 2 \\
S2 & 40 & 5 & 2000 & 40 & 0.50 & 0.70 & 0.05 & 10 & 4 & 1500 & 0.90 & 10 & 3 \\
S3 & 40 & 10 & 2000 & 40 & 0.70 & 0.70 & 0.05 & 20 & 3 & 1500 & 0.85 & 10 & 3 \\
S4 & 20 & 5 & 1000 & 40 & 0.70 & 0.50 & 0.05 & 20 & 3 & 1500 & 0.90 & 15 & 3 \\
S5 & 40 & 15 & 2000 & 60 & 0.50 & 0.50 & 0.05 & 20 & 3 & 1500 & 0.85 & 15 & 2 \\
S6 & 20 & 10 & 1000 & 70 & 0.50 & 0.70 & 0.05 & 10 & 3 & 1500 & 0.80 & 10 & 2 \\
S7 & 20 & 5 & 3000 & 60 & 0.70 & 0.50 & 0.05 & 10 & 3 & 1500 & 0.85 & 10 & 2 \\
S8 & 10 & 15 & 2000 & 50 & 0.70 & 0.70 & 0.05 & 20 & 3 & 1500 & 0.85 & 10 & 3 \\
S9 & 40 & 15 & 4000 & 60 & 0.70 & 0.70 & 0.05 & 10 & 3 & 500 & 0.80 & 15 & 1 \\
\hline \hline
\end{tabular}

The same procedure was repeated again minimizing $\mathrm{CO}_{2}$ emissions. Figure 4 shows the average $\mathrm{CO}_{2}$ emissions and the computing time. Concerning the best values for the average $\mathrm{CO}_{2}$ emissions and minimum $\mathrm{CO}_{2}$ emissions, Table 6 summarizes the statistical results. The corresponding parameters are given in Table 7. Finding the global optimum was more difficult in this case. Besides, the standard deviation was higher.

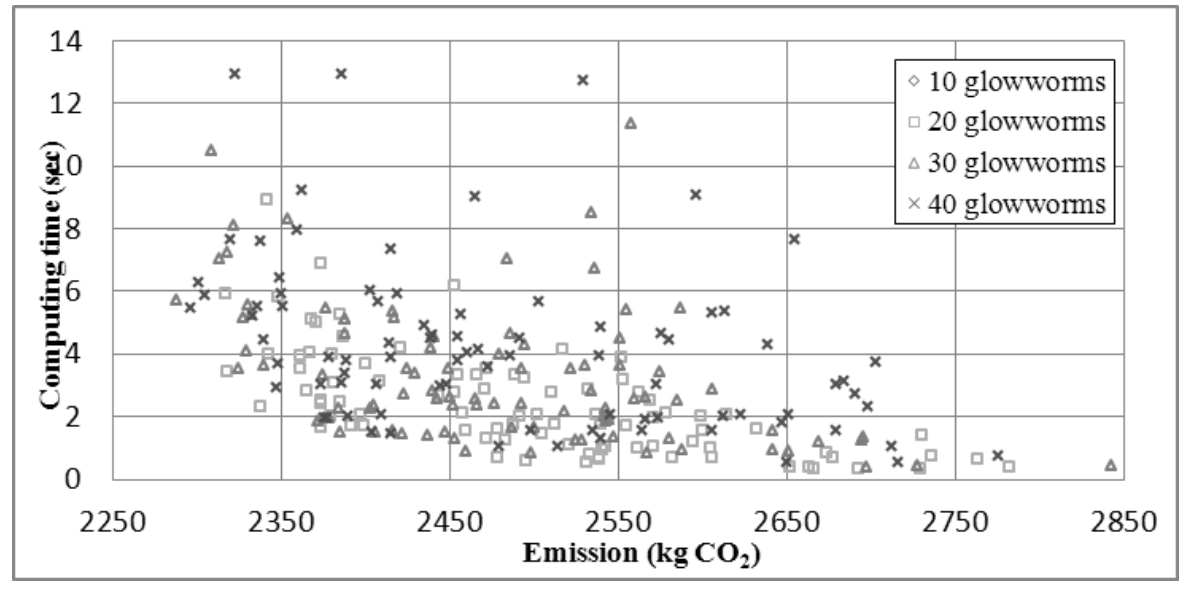

Figure 4 Average $\mathrm{CO}_{2}$ results of SAGSO. 
Table 6 Statistical results of the best values for the minimum $\mathrm{CO}_{2}$ of SAGSO.

\begin{tabular}{ccccc}
\hline \hline Solution & $\begin{array}{c}\text { Minimum emission } \\
\left(\mathrm{kg} \mathrm{CO}_{2}\right)\end{array}$ & $\begin{array}{c}\text { Average emission } \\
\left(\mathrm{kg} \mathrm{CO}_{2}\right)\end{array}$ & $\begin{array}{c}\text { Standard deviation } \\
\left(\mathrm{kg} \mathrm{CO}_{2}\right)\end{array}$ & $\begin{array}{c}\text { Average time } \\
(\mathrm{sec})\end{array}$ \\
\hline $\mathrm{S} 10$ & 2217.75 & 2349.91 & 115.89 & 1.65 \\
$\mathrm{~S} 11$ & 2317.50 & 2344.80 & 48.82 & 1.58 \\
$\mathrm{~S} 12$ & 2224.91 & 2337.74 & 79.32 & 2.29 \\
$\mathrm{~S} 13$ & 2217.75 & 2318.01 & 59.07 & 3.43 \\
$\mathrm{~S} 14$ & 2217.75 & 2317.37 & 61.26 & 5.91 \\
$\mathrm{~S} 15$ & 2217.75 & 2305.60 & 51.47 & 5.90 \\
$\mathrm{~S} 16$ & 2217.75 & 2297.07 & 70.99 & 5.49 \\
$\mathrm{~S} 17$ & 2217.75 & 2288.38 & 60.96 & 5.71 \\
\hline \hline
\end{tabular}

Table 5 Parameters of the best values for the minimum $\mathrm{CO}_{2}$ of SAGSO.

\begin{tabular}{cccccccccccccc}
\hline \hline Solution & $n$ & $n_{t}$ & $l_{0}$ & $r_{s}$ & $\varrho$ & $\gamma$ & $\beta$ & $s$ & $n_{v}$ & $M_{c}$ & $k$ & $t_{\max }$ & $n_{M}$ \\
\hline $\mathrm{S} 10$ & 10 & 5 & 1000 & 40 & 0.70 & 0.30 & 0.05 & 30 & 3 & 1000 & 0.90 & 15 & 2 \\
$\mathrm{~S} 11$ & 10 & 5 & 2000 & 30 & 0.30 & 0.30 & 0.05 & 30 & 4 & 1000 & 0.85 & 15 & 2 \\
$\mathrm{~S} 12$ & 20 & 10 & 1000 & 30 & 0.70 & 0.30 & 0.05 & 20 & 4 & 1500 & 0.80 & 15 & 1 \\
$\mathrm{~S} 13$ & 20 & 15 & 4000 & 60 & 0.70 & 0.70 & 0.05 & 20 & 4 & 1500 & 0.80 & 10 & 2 \\
$\mathrm{~S} 14$ & 20 & 10 & 3000 & 30 & 0.70 & 0.50 & 0.05 & 20 & 3 & 1500 & 0.90 & 10 & 3 \\
$\mathrm{~S} 15$ & 40 & 10 & 2000 & 70 & 0.70 & 0.50 & 0.05 & 30 & 3 & 1000 & 0.90 & 15 & 2 \\
$\mathrm{~S} 16$ & 40 & 10 & 4000 & 60 & 0.70 & 0.70 & 0.05 & 30 & 4 & 500 & 0.90 & 15 & 2 \\
$\mathrm{~S} 17$ & 30 & 5 & 2000 & 30 & 0.70 & 0.70 & 0.05 & 30 & 4 & 1000 & 0.90 & 15 & 2 \\
\hline \hline
\end{tabular}

Comparing the cost-optimized beam with the emission-optimized beam (Table 8), it is worth noting that emission-optimized beam has a larger section, with a greater amount of concrete and less steel. The exposed surface area of the emission-optimized beam was nearly double, since the algorithm searched maximizing the $\mathrm{CO}_{2}$ capture. Concrete cover was $35 \mathrm{~mm}$, the maximum allowed. Concerning the concrete mix, the cost-optimized beam acquired 54.2 MPa SCC and emissionoptimized beam acquired 31.10 MPa CVC. The emission-optimized beam achieved $26 \%$ fewer $\mathrm{CO}_{2}$ emissions, but this solution is $65 \%$ more expensive.

Table 8 Values of variables and constraints coefficients of the optimal design.

\begin{tabular}{ccc}
\hline \hline Variable & Cost-optimized & Emission-optimized \\
\hline$h(\mathrm{~mm})$ & 1570 & 2470 \\
$b_{f s}(\mathrm{~mm})$ & 450 & 600 \\
$b_{f i}(\mathrm{~mm})$ & 300 & 1000 \\
$t_{f s}(\mathrm{~mm})$ & 150 & 150 \\
$t_{f i}(\mathrm{~mm})$ & 170 & 150 \\
$t_{w}(\mathrm{~mm})$ & 150 & 150 \\
$r(\mathrm{~mm})$ & 30 & 35 \\
$n_{1}$ & 10 & 17 \\
$n_{2}$ & 4 & 32 \\
$n_{3}$ & 1 & 1
\end{tabular}


Table 8 (continued) Values of variables and constraints coefficients of the optimal design.

\begin{tabular}{|c|c|c|}
\hline$n_{4}$ & 4 & 5 \\
\hline$n_{5}$ & 9 & 6 \\
\hline$\Phi_{1}(\mathrm{~mm})$ & 6 & 6 \\
\hline$\Phi_{2}(\mathrm{~mm})$ & 25 & 8 \\
\hline$\Phi_{3}(\mathrm{~mm})$ & 25 & 8 \\
\hline$\Phi_{4}(\mathrm{~mm})$ & 8 & 6 \\
\hline$\Phi_{5}(\mathrm{~mm})$ & 6 & 6 \\
\hline$\Phi_{6}(\mathrm{~mm})$ & 6 & 6 \\
\hline$\Phi_{7}(\mathrm{~mm})$ & 6 & 6 \\
\hline Concrete & SCC3 & CVC1 \\
\hline Deflection coef. ${ }^{1}$ & 1.00 & 9.07 \\
\hline Cracking coef. $^{1}$ & 1.52 & infinite \\
\hline Cracking coef. $^{2}$ & 3.03 & infinite \\
\hline Bending coef. ${ }^{1}$ & 1.08 & 1.00 \\
\hline Bending coef. $^{2}$ & 1.36 & 1.52 \\
\hline Transversal shear coef. $^{3}$ & 1.00 & 1.08 \\
\hline Transversal shear coef. $^{2}$ & 1.55 & 1.37 \\
\hline Longitudinal superior shear coef. & 1.64 & 1.59 \\
\hline Longitudinal inferior shear coef. & 4.21 & 1.56 \\
\hline Amount of steel (kg) & 383.14 & 353.57 \\
\hline Volume of concrete $\left(\mathrm{m}^{3}\right)$ & 4.54 & 8.44 \\
\hline Cost $(€)$ & 3155.17 & 5213.55 \\
\hline Emissions $(\mathrm{kg} \mathrm{CO})_{2}$ & 3017.14 & 2217.75 \\
\hline Service life (years) & 169.71 & 221.84 \\
\hline
\end{tabular}

1. Verification on central section

2. Verification on the boundary of two different sections

3. Verification on a section located an effective depth distance away from the edge of the support

Figure 5 shows a typical curve for $\mathrm{CO}_{2}$ emissions following SAGSO. The optimization process encompasses a SA search and a GSO movement (represented by a vertical line). While SA only makes small movements, GSO can jump to a quite different solution.

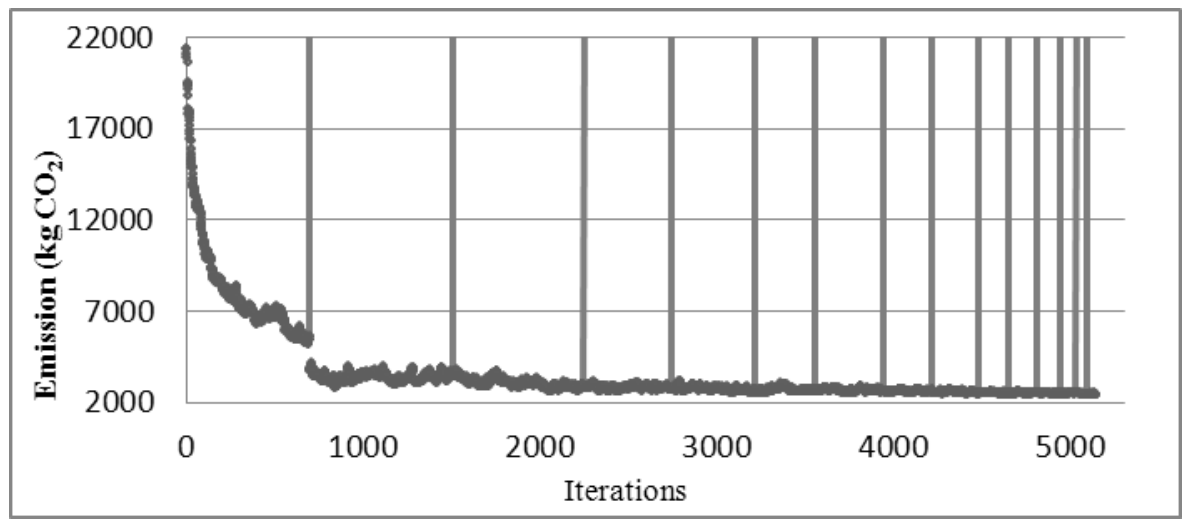

Figure 5 Typical evolution of $\mathrm{CO}_{2}$ emissions for SAGSO algorithm. 


\section{COMPARISON BETWEEN HEURISTICS}

The proposed SAGSO algorithm is compared with the SA and GSO methods. Figure 6 shows the cost optimization results with GSO. The best solution obtained with GSO was 4557.84 euros with a computing time of $8.86 \mathrm{sec}$. Therefore, SAGSO found high quality solutions with the same computing time. Concerning SA, the algorithm found the best cost-optimized and emission-optimized beam but the computer time increased 30 times.

SAGSO achieved the goal sought, which was to improve the exploitation of the algorithm. GSO provided the global searching capability and SA speeded up the local search. Its efficiency was well proven. A good calibration is needed to guarantee high quality solutions with a short computing time.

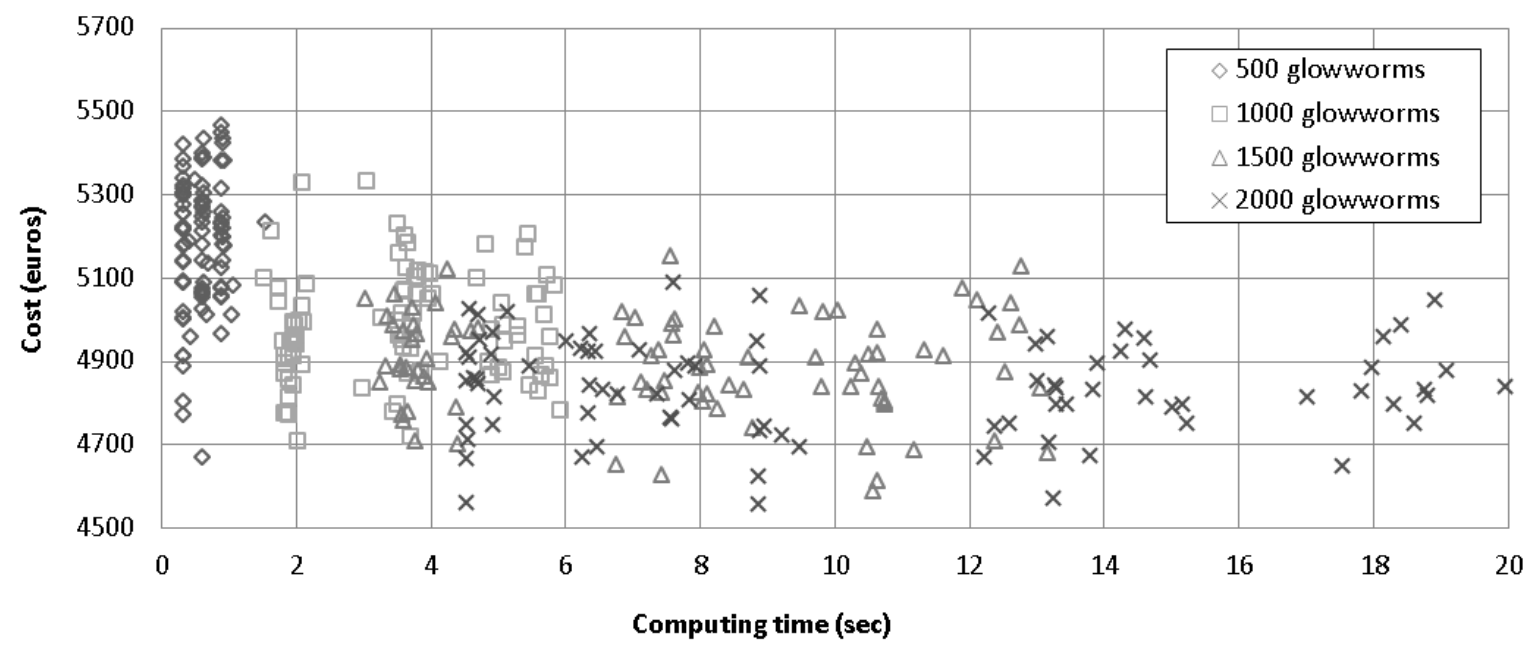

Figure 6 Average cost results of GSO

\section{CONCLUSIONS}

In this paper, a hybrid method combining simulated annealing with glowworm swarm optimization (SAGSO) algorithms is presented and employed to optimize a concrete I-beam. The algorithm minimizes the economic cost and $\mathrm{CO}_{2}$ emissions of a simply-supported concrete I-beam. The algorithm is adapted to the discrete nature of the structural variables. The findings provide evidence to suggest that large sections with a highly exposed surface area and the use of CVC with the lower strength grade can minimize the $\mathrm{CO}_{2}$ emissions.

The proposed method obtained considerably better results in terms both the quality and the computing time. SAGSO outperforms GSO in terms of efficiency, accuracy and convergence rate. The lack of feasibility and convergence to the optimum of GSO is solved thanks to the stable convergence characteristics of SA. 
Acknowledgments This work was supported by the Spanish Ministry of Science and Innovation (Research Project BIA2011-23602) and by the Universitat Politècnica de València (Research Project PAID-06-12). The authors are also grateful to Dr. Debra Westall for her thorough revision of the manuscript.

\section{References}

Ahandania, M.A., Vakil-Baghmishehb, M.T., Zadehc, M.A.B., Ghaemic, S. (2012). Hybrid particle swarm optimization transplanted into a hyper-heuristic structure for solving examination timetabling problem. Swarm Evolutionary Computation 7:21-34.

Basturk, B., Karaboga, D. (2006). An Artificial Bee Colony (ABC) algorithm for numerical function optimization. IEEE Swarm Intelligence Symposium, Indianapolis, Indiana, USA.

BEDEC. (2013). Institute of Construction Technology of Catalonia. Barcelona, Spain.

Carbonell, A., Yepes, V., González-Vidosa, F. (2012). Automatic design of concrete vaults using iterated local search and extreme value estimation. Latin American Journal of Solids and Structures 9(6):675-689.

Chen, S., Sarosh, A., Dong, Y. (2012). Simulated annealing based artificial bee colony algorithm for global numerical optimization. Applied Mathematics and Computation 219(8):3575-3589.

Collins, F. (2010). Inclusion of carbonation during the life-cycle of built and recycled concrete: influence on their carbon footprint. The International Journal of Life Cycle Assessment 15(6):549-556.

Colorni, A., Dorigo, M., Maniezzo, V. (1991). Distributed optimization by ant colonies. Proceeding of ECALEuropean Conference on Artificial Life, Elsevier, Paris, pp. 134-142.

Dutta, R., Ganguli, R., Mani, V. (2011). Swarm intelligence algorithms for integrated optimization of piezoelectric actuator and sensor placement and feedback gains. Smart Materials and Structures 20(10) 105018.

EFCA. (2006a). Environmental Product Declaration (EPD) for Normal Plasticising admixtures. Environmental Consultant, Sittard. http://www.efca.info/downloads/324\%20ETG\%20Plasticiser\%20EPD.pdf, (acessed January 2013).

EFCA. (2006b). Environmental Product Declaration (EPD) for Superplasticising admixtures. Environmental Consultant, Sittard. http://www.efca.info/downloads/325\%20ETG\%20Superplasticiser\%20EPD.pdf, (accessed January 2013).

Fan, S.K.S., Zahara, E. (2007). A hybrid simplex search and particle swarm optimization for unconstrained optimization. European Journal of Operational Research 181(2):527-548.

Fomento, M. (2008). EHE: Code of structural concrete. Ministerio de Fomento, Madrid [in Spanish].

García-Segura, T., Yepes, V., Alcalá, J. (2014). Life-cycle greenhouse gas emissions of blended cement concrete including carbonation and durability. The International Journal of Life Cycle Assessment 19(1):3-12.

Gong, Q.Q., Zhou, Y.Q., Yang, Y. (2011). Artificial Glowworm Swarm Optimization Algorithm for Solving 0-1 Knapsack Problem. Advanced Materials Research 143-144:166-171.

Hare, W., Nutini, J., Tesfamariam, S. (2013). A survey of non-gradient optimization methods in structural engineering. Advances in Engineering Software 59:19-28.

He, S., Prempain, E., Wu, Q. (2004). An improved particle swarm optimizer for mechanical design optimization problems. Engineering Optimization 36(5):585-605.

Karaboga, D., Basturk, B. (2008). On the performance of Artificial Bee Colony (ABC). Applied Soft Computing 8(1):687-697.

Kennedy, J., Eberhart, R. (1995). Particle swarm optimization. Proceedings of IEEE International Conference on Neural Networks, Piscataway, NJ, pp. 1942-1948. 
Khan, K., Sahai, A. (2012). A Glowworm Optimization Method for the Design of Web Services. International Journal of Intelligent Systems and Applications 4(10):89-102.

Kicinger, R., Arciszewski, T., De Jong, K. (2005). Evolutionary computation and structural design: a survey of the state-of-the-art. Computers \& Structures 83(23-24):1943-1978.

Kirkpatrick, S., Gelatt, C.D., Vecchi, M.P. (1983). Optimization by simulated annealing. Science 220(4598):671680

Koide, R. M., de França, G.Z., Luersen, M.A. (2013). An ant colony algorithm applied to lay-up optimization of laminated composite plates. Latin American Journal of Solids and Structures 10(3):491-504.

Krishnanand, K.N., Ghose, D. (2009). Glowworm swarm optimization: a new method for optimizing multi-modal functions. International Journal of Computational Intelligence Studies 1(1):93-119.

Lagerblad, B. (2005). Carbon dioxide uptake during concrete life-cycle: State of the art. Swedish Cement and Concrete Research Institute, Stockholm, Sweden.

Li, L.J., Huang, Z.B., Liu, F. (2009). A heuristic particle swarm optimization method for truss structures with discrete variables. Computers \& Structures 87(7-8):435-443.

Liao, W., Kao, Y., Li, Y. (2011). A sensor deployment approach using glowworm swarm optimization algorithm in wireless sensor networks. Expert Systems with Applications 38(10):12180-12188.

Luo, Q.F., Zhang, J.L. (2011). Hybrid Artificial Glowworm Swarm Optimization Algorithm for Solving Constrained Engineering Problem. Advanced Materials Research 204-210:823-827.

Martí, J.V., González-Vidosa, F., Yepes, V., Alcalá, J. (2013). Design of prestressed concrete precast road bridges with hybrid simulated annealing. Engineering Structures 48:342-352.

Martínez-Martín, F., González-Vidosa, F., Hospitaler, A., Yepes, V. (2013). A parametric study of optimum tall piers for railway bridge viaducts. Structural Engineering and Mechanics 45(6):723-740.

Medina, J. (2001). Estimation of incident and reflected waves using simulated annealing. ASCE Journal of Waterway, Port, Coastal, and Ocean Engineering 127(4):213-221.

Parsopoulos, K., Vrahatis, M. (2002). Recent approaches to global optimization problems through particle swarm optimization. Natural Computing 1(2-3):235-306.

Payá-Zaforteza, I., Yepes, V., González-Vidosa, F., Hospitaler, A. (2010). On the Weibull cost estimation of building frames designed by simulated annealing. Meccanica 45(5):693-704.

Qu, L., He, D., Wu, J. (2011). Hybrid Coevolutionary Glowworm Swarm Optimization Algorithm with Simplex Search Method for System of Nonlinear Equations. Journal of Information \& Computational Science 8(13):26932701.

Sarma, K.C., Adeli, H. (1998). Cost optimization of concrete structures. ASCE Journal of Structural Engineering 124(5):570-578.

SENDECO2. (2013). http://www.sendeco2.com/es/precio_co2.asp?ssidi=1, (accessed January 2013).

Shieh, H.L., Kuo, C.C., Chiang, C.M. (2011). Modified particle swarm optimization algorithm with simulated annealing behavior and its numerical verification. Applied Mathematics and Computation 218(8):4365-4383.

Sideris, K.K., Anagnostopoulos, N.S. (2013). Durability of normal strength self-compacting concretes and their impact on service life of reinforced concrete structures. Construction and Building Materials 41:491-497.

Torres-Machí, C., Yepes, V., Alcalá, J., Pellicer, E. (2013). Optimization of high-performance concrete structures by variable neighborhood search. International Journal of Civil Engineering 11(2):90-99.

Tuutti, K. (1982). Corrosion of steel in Concrete. CBI Forskning Research Report. Cement and Concrete Research Institute, Stockholm, Sweden.

Valdez, F., Melin, P., Castillo, O. (2011). An improved evolutionary method with fuzzy logic for combining Particle Swarm Optimization and Genetic Algorithms. Applied Soft Computing 11(2):2625-2632. 
Wang, H., Sun, H., Li, C., Rahnamayan, S., Pan, J. (2013). Diversity enhanced particle swarm optimization with neighborhood search. Information Sciences 223(20):119-135.

Yang, Y., Zhou, Y., Gong, Q. (2010). Hybrid Artificial Glowworm Swarm Optimization Algorithm for Solving System of Nonlinear Equations. Journal of Computational Information Systems 6(10):3431-3438.

Yepes, V., González-Vidosa, F., Alcalá, J., Villalba, P. (2012). CO CO$^{-}$Optimization design of reinforced concrete retaining walls based on a VNS-threshold acceptance strategy. ASCE Journal of Computing in Civil Engineering 26(3):378-386.

Zhang, J., Zhou, G., Zhou, Y. (2010). A New Artificial Glowworm Swarm Optimization Algorithm Based on Chaos Method. B.Y. Cao, S. Chen, G. Wang and S. Guo, (eds.) Quantitative Logic and Soft Computing, AISC 82, Springer-Verlag, Heidelberg, pp. 683-693. 